\title{
Portable NIV for patients with moderate to severe COPD: two randomized crossover trials
}

\author{
Daniel Sebastian Majorski', Friederike Sophie Magnet ${ }^{1}$, Saadia Thilemann ${ }^{1}$, Claudia Schmoor $^{2}$, \\ Wolfram Windisch ${ }^{1 *}$ and Sarah Bettina Schwarz ${ }^{1}$ (I)
}

\begin{abstract}
Background: Long-term non-invasive ventilation (NIV) is as an established treatment option for chronic hypercapnic COPD patients. Beneficial effects have also been shown during exercise, but this is restricted to rehabilitation programs. New portable NIV (pNIV) devices may now enable NIV application during walking at home.

Study design and methods: In two randomized crossover trials, the impact of pNIV on dyspnea and endurance capacity was investigated in patients with moderate to severe COPD. Participants performed a standardized 6-min walking test, with and without pNIV, using a pre-set inspiratory/expiratory positive airway pressure of $18 / 8 \mathrm{cmH}_{2} \mathrm{O}$. The first study was performed in NIV-naïve patients (Study I), while the second study was performed in those already established on long-term NIV (Study II).

Results: 38 patients ( $66.9 \pm 7.4$ years, mean $\mathrm{FEV}_{1}: 30.3 \pm 8 \%$ pred) and 23 patients $\left(67.6 \pm 8.7\right.$ years, mean $\mathrm{FEV}_{1}$ : $29.8 \pm 10.4 \%$ pred) participated in Study I and II, respectively. In Study I, the mean difference in the Borg Dyspnea Scale (BDS, primary outcome) score following walking was 3.2 (IQR 2-4) without pNIV, compared to 2.6 (IQR 1-4) with pNIV $(\triangle B D S 0.65, P=0.04)$, while walking distance increased from $311.8 \mathrm{~m}(95 \% \mathrm{Cl} 276.9-346.6 \mathrm{~m})$ to $326.3 \mathrm{~m}(95 \% \mathrm{Cl}$ 291.5-361.2 m) $(P=0.044)$ when pNIV was used. Accordingly, in Study II, the mean difference in BDS was 4.4 (IQR 3-6) without pNIV, compared to 4.5 (IQR 3-6) with pNIV ( $\triangle \mathrm{BDS} 0.09, P=0.54)$, while walking distance decreased from $291.5 \mathrm{~m}(95 \% \mathrm{Cl} 246.1-336.9 \mathrm{~m})$ to $258.4 \mathrm{~m}(95 \% \mathrm{Cl} 213-303.8 \mathrm{~m})(P \leq 0.001)$.

Interpretation: The use of a pNIV device during walking can improve dyspnea and walking distance in patients with moderate to severe COPD. Patients who do not already receive long-term NIV therapy are more likely to benefit compared to those undergoing long-term NIV. Careful patient selection is mandatory.

Clinical Trial Register: DRKS00013203; DRKS00012913 registered October 20th 2017 and October 16th 2017; https:// www.drks.de/drks_web/
\end{abstract}

Keywords: COPD, Respiratory insufficiency, Endurance capacity, Non-invasive ventilation

\section{Background}

The delivery of non-invasive ventilation (NIV) via a facemask serves as an established treatment option for patients with chronic hypercapnic respiratory failure,

\footnotetext{
*Correspondence: windischw@kliniken-koeln.de

${ }^{1}$ Department of Pneumology, Cologne Merheim Hospital, Kliniken der

Stadt Köln gGmbH, Witten/Herdecke University, Faculty of Health/School of Medicine, Cologne, Germany

Full list of author information is available at the end of the article
}

which can arise from a number of different etiologies including COPD [1-3]. For this purpose, NIV is typically used intermittently in a nocturnal setting-an approach that is capable of improving long-term survival and health-related quality of life [1]. In COPD patients, the use of NIV with ventilator settings that are high enough to normalize/improve hypercapnia has been established as the treatment modality of choice $[4,5]$. original author(s) and the source, provide a link to the Creative Commons licence, and indicate if changes were made. The images or other third party material in this article are included in the article's Creative Commons licence, unless indicated otherwise in a credit line to the material. If material is not included in the article's Creative Commons licence and your intended use is not permitted by statutory regulation or exceeds the permitted use, you will need to obtain permission directly from the copyright holder. To view a copy of this licence, visit http://creativecommons.org/licenses/by/4.0/. The Creative Commons Public Domain Dedication waiver (http://creativeco mmons.org/publicdomain/zero/1.0/) applies to the data made available in this article, unless otherwise stated in a credit line to the data. 
In addition, NIV can also be used during physical activity, particularly in patients with COPD [6-8]. This serves to improve the outcome of rehabilitation therapy [9], and can also be used during walking in the home environment to improve exercise capacity and dyspnea. Accordingly, several studies carried out in various clinical settings have clearly shown that NIV-aided walking improves dyspnea, walking distance and gas exchange [10-14].

However, one major problem in transferring this experimentally positive result to the home environment is the fact that applying NIV techniques during walking can be laborious and cumbersome, since this form of therapy was originally developed for use during rest. For example, the use of a rollator [12] or backpack [15] to carry the NIV device is suggested to restrict the patient's range of motion and is therefore detrimental to its application in the home environment.

In order to overcome the burden of heavy ventilators, portable NIV devices (pNIV) have been developed. These products are generally used as hand-held devices, which can be carried in one hand. Thereby, most of the restrictions caused by the heavy home-NIV devices can be easily overcome. Of note, a recent pilot study of COPD patients was able to demonstrate that the use of pNIV with a preset inspiratory positive airway pressure (IPAP) of $18 \mathrm{cmH}_{2} \mathrm{O}$ and a preset expiratory positive airway pressure (EPAP) of $8 \mathrm{cmH}_{2} \mathrm{O}$ is capable of reducing the recovery time of dyspnea after exercise [16]. Therefore, this study showed that pNIV has the potential to improve exercise capacity.

However, it remains unclear exactly how pNIV improves exercise performance. In addition, the patient groups that would benefit most from pNIV use in terms of disease severity need to be identified. Therefore, the present study aimed to test the hypothesis that pNIV is capable of improving both dyspnea and walking distance in patients with COPD. It was further hypothesized that the success of pNIV is dependent on disease severity. To address these questions, two different randomized cross-over trials were performed in COPD patients with moderate to severe airflow limitation using a comparable study design. Patients without established long-term NIV formed the cohort for the first study, while long-term NIV patients formed the cohort for the second study.

\section{Material and methods}

Two crossover randomized trials with different study populations but an identical study design were performed at the Department of Pneumology, Lung Clinic, Cologne Merheim Hospital, Witten/Herdecke University, Germany. Both study protocols were approved by the ethics committee at Witten/Herdecke University. The studies were performed in accordance with the ethical standards laid down in the Declaration of Helsinki [17] and were separately registered at the German Clinical Trials Registry (DRKS00012913: Study I; DRKS00013203: Study II). All patients provided written informed consent.

\section{Patients}

COPD patients were included if they presented a moderate to severe airflow limitation which, according to the Global Initiative for Obstructive Lung Disease (GOLD), was defined by a forced expiratory volume in one second $\left(\mathrm{FEV}_{1}\right)<50 \%$ predicted [18]. The first study (Study I) consisted of COPD patients (COPD stages GOLD III and IV) without chronic hypercapnic respiratory failure (DRKS00012913). The second study (Study II, DRKS00013203) consisted of patients with established long-term NIV aimed at treating hypercapnic respiratory failure, as per German medical guidelines [2, 3]. Only patients receiving long-term NIV for more than 3 months were included in Study II. In contrast, being on longterm NIV for any time served as a strict exclusion criterion for study I. In addition, patients with CPAP therapy were excluded in both studies. At the time of recruitment, patients were undergoing optimal inhalative therapy [19] and no subsequent changes to medication were made during the trial. All patients were required to be free of exacerbation-which was defined by any medical treatment aggravation including antibiotics and systemic corticosteroids-at least 4 weeks prior to study inclusion [19]. In addition, patients with any type of unsteadiness or advancing difficulties in walking were excluded.

\section{Study design and measurements}

Prior to exercise testing, patients underwent a familiarization session for the pNIV, which included detailed instructions on how to handle the device as well as a practice session lasting at least $30 \mathrm{~min}$. For exercise testing, a 6-min walking test (6MWT) was performed according to previous recommendations [20]. When necessary, long-term oxygen therapy (LTOT) was used during walking using flow rates that were prescribed prior to study enrollment. Blood gas analysis (ABL 90, Radiometer GmbH, Willich, Germany), spirometry, full body plethysmography, and respiratory muscular function testing was performed (ZAN500 Bodyplethysmograph, ZAN Austria, Winkling, Austria). For both crossover trials, patients were randomly assigned to exercise with and without the PNIV device using two crossover sequences:."Period 1: 6MWT with pNIV/Period 2: 6MWT without pNIV" and "Period 1: 6MWT without pNIV/Period 2: 6MWT with pNIV". Patients were free to decide when and how often they wanted use the pNIV device during their walking sessions. 


\section{Portable non-invasive ventilation (pNIV)}

The certified medical device 'VitaBreath' (Philips, Respironics, Murrysville, PA, USA) was used as the pNIV device for the purpose of both studies. It is a hand-held device specifically designed to provide COPD patients with positive pressure via a mouth piece, during or after exercise, in order to relieve breathlessness caused by physical exertion (Fig. 1) [21]. The pNIV device provides two fixed pressure levels: $18 \mathrm{cmH}_{2} \mathrm{O}$ during inspiration and $8 \mathrm{cmH}_{2} \mathrm{O}$ during expiration.

\section{Statistical analysis}

The primary endpoint was the difference in the Borg Dyspnea Scale (BDS) score before and after exercise. This decision was based on the observation that exercise in these patients is severely restricted by symptoms and also on the acceptation that using external devices during physical activity in clinical practice will only occur in case of patients subjectively benefitting from the intervention. In each study, the hypothesis that there is no difference in dyspnea between interventions was tested at two-sided level alpha $=0.05$ against the alternative hypothesis that there is a difference.

For sample size calculation based on the BDS score, a standard deviation of 3 points was assumed, and the difference between interventions was assumed as 1.5 points in study I and as 2 points in study II. This resulted in a required sample size of 38 patients in study I and of 22 patients in study II to achieve a power of $80 \%$. In the analysis, exact 2-sample Wilcoxon tests of crossover differences at two-sided level alpha $=0.05$ were used. In addition, tests of period and of carryover effects (i.e. an interaction between intervention and period) were performed using exact Wilcoxon tests.

Walking distance, blood gas analysis, blood pressure and heart rate served as secondary outcomes. The effects of the intervention on these secondary endpoints were evaluated using linear regression models. The factors intervention, period and randomized sequence were included as fixed effects, and the patient within the randomized sequence was included as a random effect. The effects of the intervention were estimated with 95\% confidence intervals and tested at the two-sided level alpha $=0.05$. Furthermore, tests for a period effect and carryover effects were performed in these models. No alpha adjustment was performed for the multiple testing of the secondary endpoints. The p-values of the statistical tests of effects on the secondary endpoints should be interpreted in the context of a descriptive analysis.

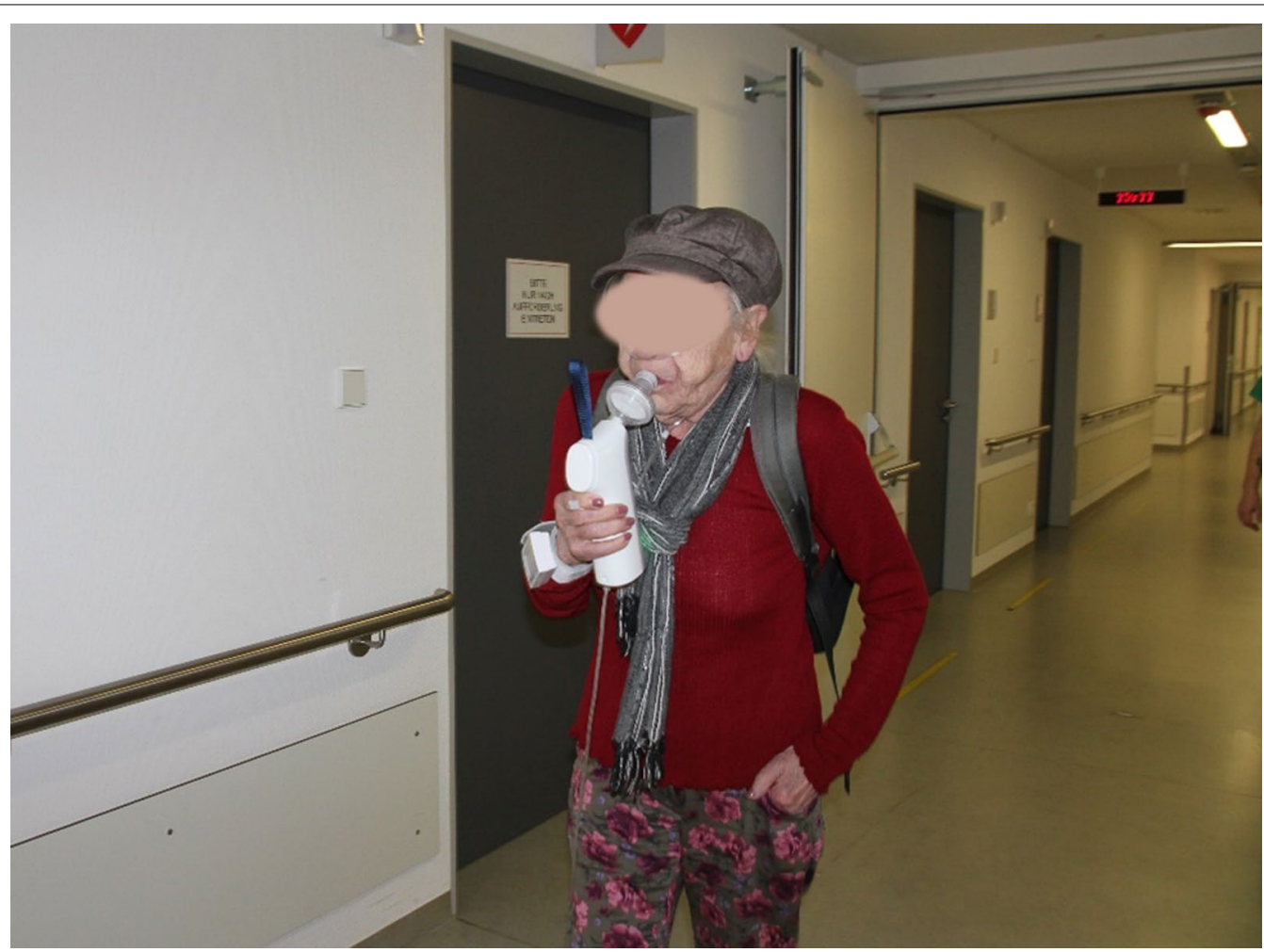

Fig. 1 A patient using the pNIV device while completing a 6-min walking test 


\section{Results}

Out of the 94 patients with severe COPD who were screened, 61 patients met the inclusion criteria and were consecutively enrolled (Fig. 2a and b). Demographic data, blood gases, data on bodyplethysmography and respiratory muscle function testing are presented in Table 1 . The ventilator settings used for established long-term NIV therapy were as follows: an IPAP level of $23.7 \pm 3.8$
$\mathrm{cmH}_{2} \mathrm{O}$ (IQR 20.25-26.75) and an EPAP level of $5.5 \pm 1$ $\mathrm{cmH}_{2} \mathrm{O}$ (IQR 5-6). The results of the blood gas analyses, pulseoximetry and blood pressure measurement for each of the exercise testing sequences (with or without the pNIV device) are illustrated in Tables 2 and 3.

In study I, the results of the mean BDS difference before and after exercise (primary endpoint) were 3.2 $(\mathrm{SD} \pm 1.5, \mathrm{IQR} 2-4)$ without pNIV compared to 2.6

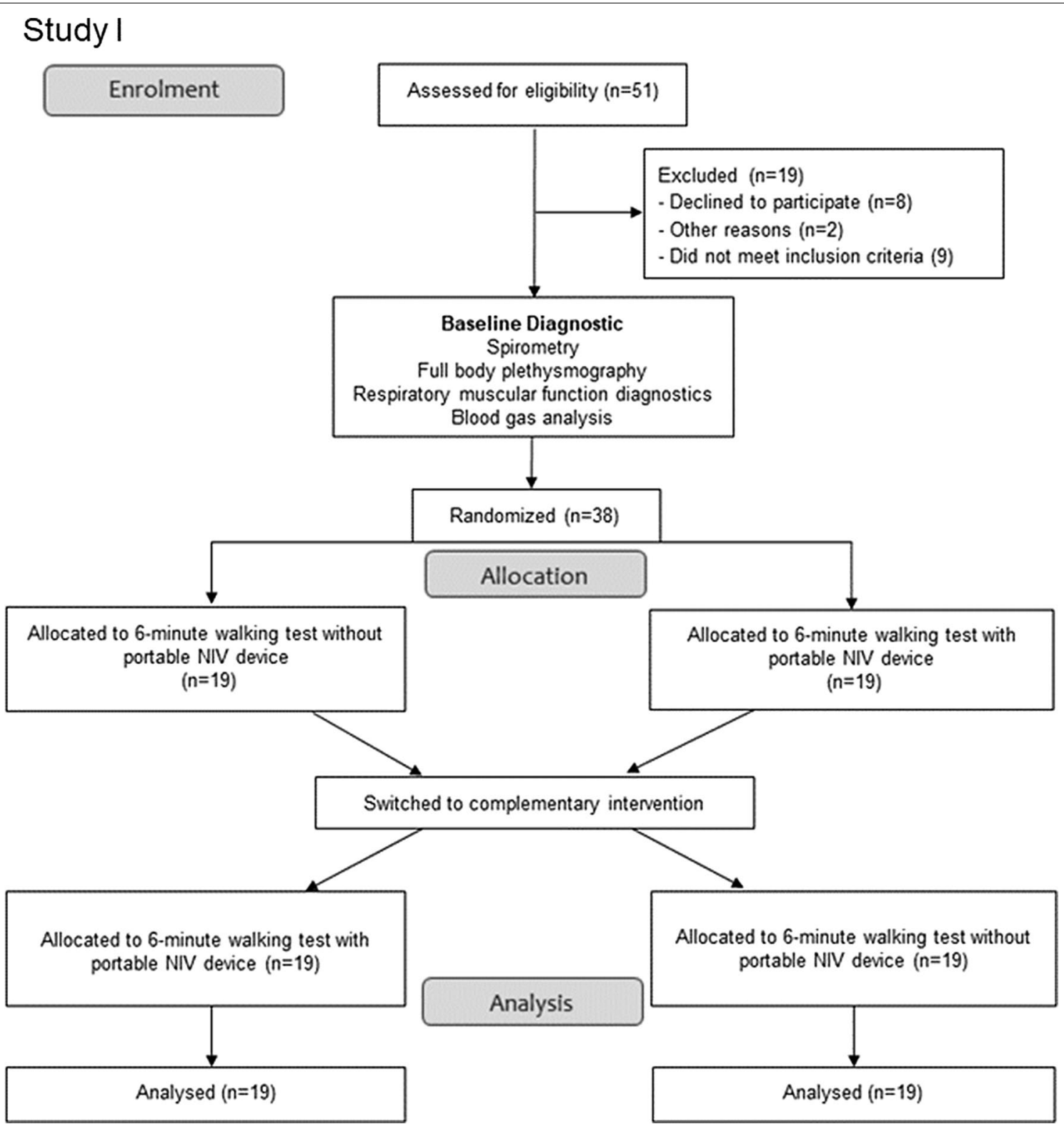

Fig. 2 a CONSORT flow diagram of the study enrolment process (Study I) [27]. b CONSORT flow diagram of the study enrolment process (Study II) [27]. The discrepancy between the sample size calculation and the final recruitment size is due to the recruitment process. There was no post-recruitment 


\section{Study II}

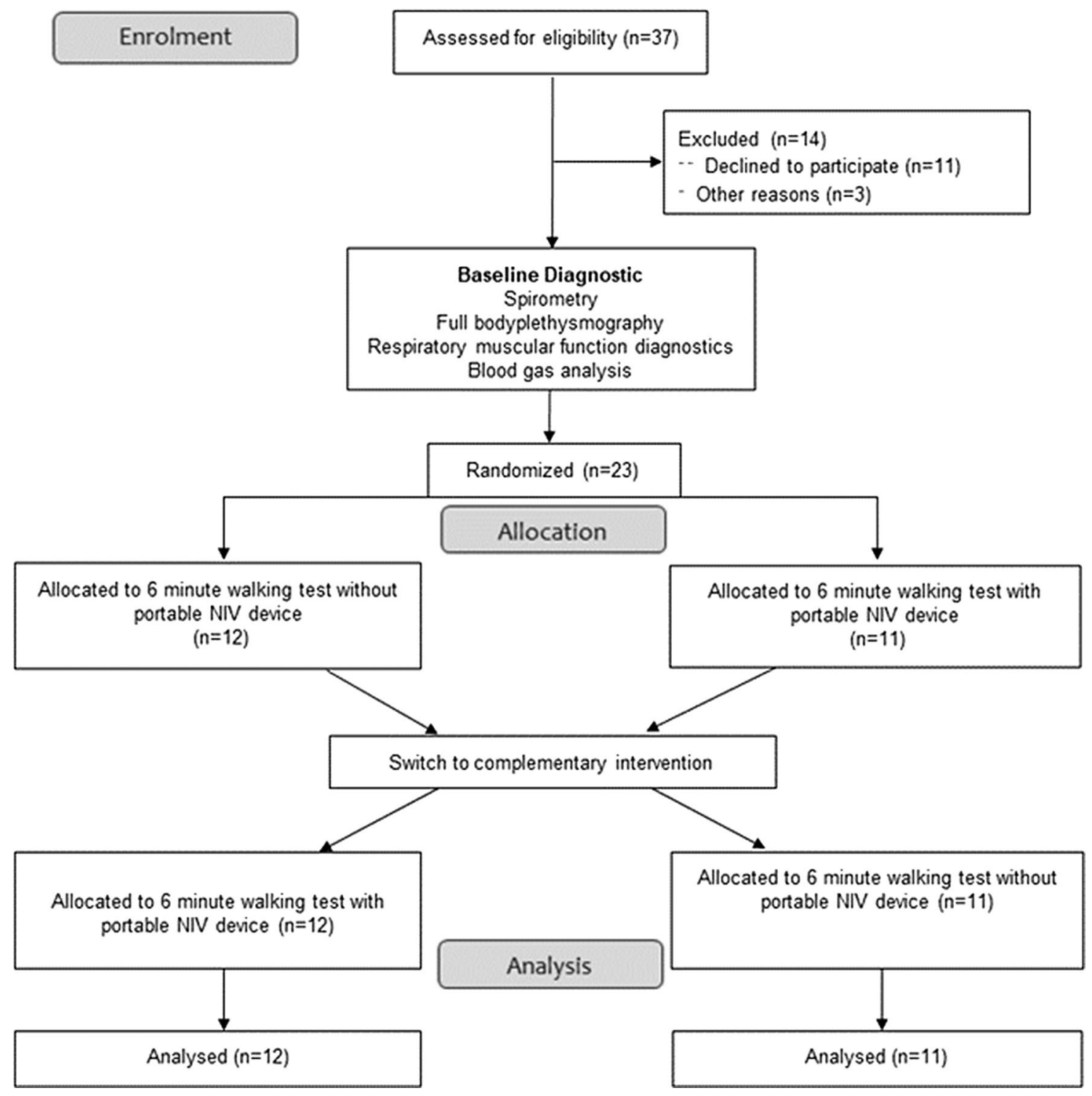

Fig. 2 continued

$(\mathrm{SD} \pm 1.8, \mathrm{IQR} 1-4)$ with pNIV. This led to a mean BDS difference between the intervention and control groups of 0.65 ( $\mathrm{SD} \pm 1.7, \mathrm{p}=0.041$ ) for Study I (Fig. 3a). Within the cohort that had already adapted to long-term NIV (Study II), the group without the pNIV showed a mean BDS difference of 4.4 ( $\mathrm{SD} \pm 1.85$; IQR: $3-6)$, while the group with the pNIV had a BDS value of $4.5(\mathrm{SD} \pm 1.9$; IQR 3-6); this revealed that there were no significant differences between the two treatment interventions (0.09; $\mathrm{SD} \pm 1.7 ; \mathrm{p}=0.55$ ) (Fig. 3b). However, the results varied considerably amongst individual patients, with dyspnea being substantially reduced or even aggravated when using the pNIV system (Fig. 4a and b).

Regarding the effect of intervention on walking distance, the use of the pNIV device led to a statistically significant improvement in the 6MWT in Study I (14.6 m; $\mathrm{p}=0.044)$, but was associated with a significant deterioration in walking performance in Study II $(-33.1 \mathrm{~m}$; $\mathrm{p} \leq 0.001$ ) (Fig. 5a, b). In Study I, 60.6\% of participants reported that they benefitted subjectively from using the device, while $39.4 \%$ did not experience any benefits. Two patients who had shown a deterioration in their BDS score versus six patients with no difference in their 
Table 1 Patient characteristics at baseline in Studies I and II

\begin{tabular}{|c|c|c|c|c|}
\hline & $\begin{array}{l}\text { Total } \\
(\mathrm{N}=61)\end{array}$ & $\begin{array}{l}\text { Study I* } \\
(N=38)\end{array}$ & $\begin{array}{l}\text { Study II" } \\
(\mathrm{N}=23)\end{array}$ & $P$ \\
\hline Age [years] & $67 \pm 8$ & $66.9 \pm 7.4$ & $67.6 \pm 8.7$ & 0.74 \\
\hline Female gender [\%] & 37.7 & 32 & 47.8 & 0.25 \\
\hline $\mathrm{FEV}_{1}[\%$ pred] & $30.3 \pm 8.9$ & $30.3 \pm 8$ & $29.8 \pm 10.4$ & 0.99 \\
\hline $\mathrm{FEV}_{1}$ [liter] & $0.85 \pm 0.26$ & $0.88 \pm 0.26$ & $0.78 \pm 0.25$ & 0.25 \\
\hline FVC [\%pred] & $66.25 \pm 18.9$ & $63.2 \pm 19.9$ & $70.8 \pm 15.7$ & 0.13 \\
\hline FVC [liter] & $2.37 \pm 0.86$ & $2.4 \pm 0.9$ & $2.31 \pm 0.81$ & 0,67 \\
\hline $\mathrm{FEV}_{1} / \mathrm{FVC}$ ratio [\%] & $37 \pm 10.4$ & $37.5 \pm 10.3$ & $35.7 \pm 10.4$ & 0.31 \\
\hline TLC [\%pred] & $117.6 \pm 20.9$ & $117.7 \pm 18.8$ & $117.3 \pm 23.9$ & 0.94 \\
\hline RV [\%pred] & $202.5 \pm 54.7$ & $203.7 \pm 49.6$ & $200.5 \pm 68.5$ & 0.84 \\
\hline $\mathrm{P} 0.1[\mathrm{kPa}]$ & $0.48 \pm 0.25$ & $0.53 \pm 0.25$ & $0.42 \pm 0.14$ & 0.25 \\
\hline PImax [kPa] & $5.5 \pm 22.3$ & $5.9 \pm 2.3$ & $4.9 \pm 2$ & 0.16 \\
\hline PEmax [kPa] & $10.0 \pm 3.9$ & $9.6 \pm 3.7$ & $10.7 \pm 4.1$ & 0.41 \\
\hline Nasal sniff [kPa] & $4.8 \pm 1.5$ & $5.4 \pm 1.5$ & $4.1 \pm 1.6$ & 0.01 \\
\hline $\begin{array}{l}\text { Cumulative smok- } \\
\text { ing dosage [pack } \\
\text { years] }\end{array}$ & $53.1 \pm 23.6$ & $55.2 \pm 23.4$ & $49.8 \pm 23.4$ & 0.32 \\
\hline BMI $\left[\mathrm{kg} / \mathrm{m}^{2}\right]$ & $26.6 \pm 5.9$ & $24.5 \pm 3.9$ & $30 \pm 6.9$ & 0.003 \\
\hline $\mathrm{pH}$ & $7.42 \pm 0.03$ & $7.42 \pm 0.03$ & $7.41 \pm 0.03$ & 0.4 \\
\hline $\mathrm{PaO}_{2}[\mathrm{mmHg}]$ & $65.8 \pm 11.7$ & $60.6 \pm 6.8$ & $74.3 \pm 13$ & $<0.001$ \\
\hline $\mathrm{PaCO}_{2}[\mathrm{mmHg}]$ & $42.4 \pm 6.1$ & $41.3 \pm 6.9$ & $44.4 \pm 3.6$ & 0.01 \\
\hline $\mathrm{HCO}_{3}{ }^{-}[\mathrm{mmol} / \mathrm{l}]$ & $27 \pm 2.4$ & $26.3 \pm 2.2$ & $28.2 \pm 2.3$ & 0.01 \\
\hline $\begin{array}{l}\text { Supplemental } \\
\text { oxygen [\% of } \\
\text { patients]; [l/ } \\
\text { min] }]^{* *}\end{array}$ & $38.3 ; 2.6 \pm 1.2$ & $18.4 ; 1.9 \pm 0.6$ & $76 ; 3 \pm 1.3$ & $<0.001$ \\
\hline
\end{tabular}

$F E V_{1}$ forced expiratory volume in one second, $F V C$ forced vital capacity, $R V$ residual volume, $T L C$ total lung capacity, $B M I$ body mass index, $\mathrm{PaO}_{2}$ partial pressure of arterialized oxygen, $\mathrm{PaCO}_{2}$ partial pressure of arterialized carbon dioxide, $\mathrm{HCO}_{3}{ }^{-}$arterialized standard hydrogen carbonate

*Patients without long-term NIV; **Only $\mathrm{O}_{2}$ dependent patients

"Patients with long-term NIV

${ }^{\curlyvee} 40$ patients were ex-smokers, 21 patients were active smokers;

BDS score said they had benefitted subjectively from pNIV. In a subgroup of 15 patients (Study II) who had a maximal inspiratory pressure (PImax) below $6.0 \mathrm{kPa}, 12$ of these preferred using the device while walking, while the remaining 3 did not. In a subgroup of 20 (out of 61) patients with rather low relative hyperinflation (RV/ TLC $<60 \%$ ), the mean difference in BDS was 3.9 without the pNIV device, and 3.8 when walking was aided by pNIV.

\section{Discussion}

Our two randomized cross-over trials investigated the effects of a pNIV device on exercise capacity and dyspnea in COPD patients with moderate to severe airflow limitation. The major findings are as follows:

Firstly, pNIV use was found to significantly improve exercise performance in COPD patients with moderate to severe airflow limitation. This specifically pertained to improvements in both dyspnea and walking distance following a $6 \mathrm{MWT}$. However, these positive effects were only observed in patients who had not become dependent on long-term NIV that had been prescribed for treating hypercapnic respiratory failure.

Secondly, in contrast to non-NIV patients, those with established long-term NIV generally did not benefit from pNIV-aided walking. Here, even walking distance and gas exchange were shown to be detrimentally affected when walking was pNIV-aided.

The current finding has several important clinical considerations. Despite reaching statistical significance, the improvements in exercise performance in the non-NIV group did not reach the internationally accepted minimal clinically important difference (MCID). Here, BDS significantly improved by $0.65(\mathrm{MCID}=1)$ [22], while the walking distance significantly improved by $15 \mathrm{~m}$ $(\mathrm{MCID}=25-35 \mathrm{~m})$ [23]. Based on these findings, the use of a pNIV device to assist the patient during exercise cannot be generally recommended.

It should be noted, however, that outcome varied considerably amongst individual patients. For example, the BDS score in the non-NIV group did indeed improve by at least 1 point in 20 patients (52.6\%). Substantial $(\triangle \mathrm{BDS} \geq 2)$ and even enormous $(\triangle \mathrm{BDS} \geq 3)$ improvements were seen in $12(31.6 \%)$ and 4 patients $(10.5 \%)$ in this cohort, respectively. Furthermore, even in the second group of patients who had been established on longterm NIV, clinically important improvements in BDS $(\triangle \mathrm{BDS} \geq 1)$ were observed in 8 patients $(33.3 \%)$. Therefore, these two studies clearly show that pNIV is capable of improving exercise performance in selected COPD patients with moderate to severe airflow limitation.

The present trials also attempted to identify and define the subgroups of COPD patients that would/would not potentially benefit from pNIV use during exercise. Indeed, the current results clearly show that patients already receiving long-term NIV therapy are less likely to benefit than those who have similar lung function impairments but are not undergoing long-term NIV. This is remarkable as patients already acclimatized to positive pressures during respiration are presumed to be able to adapt more easily to pNIV. However, the opposite might also be true, since the long-term NIV patients in the current trial were already accustomed to a type of high-intensity NIV that used higher pressures than those applied during the 6MWT in the current study. Here, pNIV was restricted to $18 \mathrm{cmH}_{2} \mathrm{O}$ (the fixed inspiratory pressure level provided by the device), whereas longterm NIV patients received mean inspiratory pressures of $24 \mathrm{cmH}_{2} \mathrm{O}$. The fact that inspiratory pressure levels might have been too low is also supported by recent findings in 
Table 2 Study I*: blood gas analyses and vital parameters after exercise $(\mathrm{N}=38)$

\begin{tabular}{|c|c|c|c|c|c|}
\hline Study I* & Period & With pNIV & Without pNIV & Treatment effect $(95 \% \mathrm{Cl})$ & $P$ \\
\hline \multirow[t]{2}{*}{$\mathrm{pH}$} & 1 & $7.42 \pm 0.04$ & $7.4 \pm 0.05$ & $-0.005[-0.01 ; 0.004]$ & 0.26 \\
\hline & 2 & $7.39 \pm 0.05$ & $7.42 \pm 0.04$ & & \\
\hline \multirow{2}{*}{$\mathrm{PaCO}_{2}[\mathrm{mmHg}]$} & 1 & $42.7 \pm 9.1$ & $41.4 \pm 6.1$ & $0.46[-0.8 ; 1.7]$ & 0.48 \\
\hline & 2 & $42.3 \pm 5.9$ & $43.2 \pm 8.4$ & & \\
\hline \multirow[t]{2}{*}{$\mathrm{PaO}_{2}[\mathrm{mmHg}]$} & 1 & $66.7 \pm 7.4$ & $61.1 \pm 8.9$ & $0.03[-1.9 ; 2]$ & 0.98 \\
\hline & 2 & $58.5 \pm 8.4$ & $63.4 \pm 8.3$ & & \\
\hline \multirow[t]{2}{*}{$\mathrm{HCO}_{3}^{-}[\mathrm{mmol} / \mathrm{l}]$} & 1 & $26.4 \pm 2.4$ & $24.8 \pm 2$ & $-0.2[-0.7 ; 0.3]$ & 0.45 \\
\hline & 2 & $24.7 \pm 2.7$ & $26.6 \pm 2.3$ & & \\
\hline \multirow[t]{2}{*}{$\mathrm{S}_{\mathrm{a}} \mathrm{O}_{2}[\%]$} & 1 & $93.6 \pm 2$ & $90.8 \pm 5.3$ & $-0.2[-1.4 ; 0.8]$ & 0.63 \\
\hline & 2 & $89.6 \pm 5$ & $92.9 \pm 2.6$ & & \\
\hline \multirow[t]{2}{*}{$\mathrm{RR}_{\text {sys }}[\mathrm{mmHg}]$} & 1 & $151.6 \pm 28.1$ & $147.8 \pm 20.6$ & $1.9[-5 ; 8.7]$ & 0.659 \\
\hline & 2 & $152.2 \pm 15.5$ & $150.2 \pm 21.6$ & & \\
\hline \multirow[t]{2}{*}{$\mathrm{RR}_{\mathrm{dia}}[\mathrm{mmHg}]$} & 1 & $92.5 \pm 16.6$ & $91.2 \pm 12.8$ & $-0.8[-6.4 ; 4.7]$ & 0.77 \\
\hline & 2 & $94.4 \pm 19.5$ & $92.9 \pm 11.5$ & & \\
\hline \multirow[t]{2}{*}{ Heart rate [/min] } & 1 & $85.5 \pm 23.2$ & $89.1 \pm 14.4$ & $0.4[-6.4 ; 7.2]$ & 0.90 \\
\hline & 2 & $90.6 \pm 12.9$ & $88 \pm 14.5$ & & \\
\hline
\end{tabular}

$\mathrm{PaO}_{2}$ partial pressure of arterialized oxygen, $\mathrm{PaCO}_{2}$ partial pressure of arterialized carbon dioxide, $\mathrm{HCO}_{3}{ }^{-}$arterialized standard hydrogen carbonate, $\mathrm{S}_{a} \mathrm{O}_{2} \mathrm{Oxygen}$ saturation, RRsys systolic blood pressure, RRdia diastolic blood pressure

*Patients without long-term NIV

Table 3 Study II": blood gas analyses and vital parameters after exercise $(\mathrm{N}=23)$

\begin{tabular}{|c|c|c|c|c|c|}
\hline Study II & Period & With pNIV & Without pNIV & Treatment effect $(95 \% \mathrm{Cl})$ & $P$ \\
\hline \multirow[t]{2}{*}{$\mathrm{pH}$} & 1 & $7.37 \pm 0.04$ & $7.38 \pm 0.02$ & $-0.01[-0.02 ;-0.001]$ & 0.033 \\
\hline & 2 & $7.38 \pm 0.03$ & $7.38 \pm 0.04$ & & \\
\hline \multirow[t]{2}{*}{$\mathrm{PaCO}_{2}[\mathrm{mmHg}]$} & 1 & $53 \pm 2.6$ & $46.2 \pm 5.3$ & $1.1[-0.04 ; 2.3]$ & 0.06 \\
\hline & 2 & $47 \pm 4.7$ & $51.9 \pm 3.3$ & & \\
\hline \multirow[t]{2}{*}{$\mathrm{PaO}_{2}[\mathrm{mmHg}]$} & 1 & $55.3 \pm 7$ & $61 \pm 13.4$ & $-3.6[-6.4 ;-0.8]$ & 0.013 \\
\hline & 2 & $57.8 \pm 9.7$ & $59.2 \pm 9.3$ & & \\
\hline \multirow[t]{2}{*}{$\mathrm{HCO}_{3}^{-}[\mathrm{mmol} / \mathrm{l}]$} & 1 & $29.8 \pm 3.2$ & $26.6 \pm 2.1$ & $-0.3[-0.9 ; 0.3]$ & 0.29 \\
\hline & 2 & $26.9 \pm 1.8$ & $29.9 \pm 2.6$ & & \\
\hline \multirow[t]{2}{*}{$\mathrm{S}_{\mathrm{a}} \mathrm{O}_{2}[\%]$} & 1 & $88 \pm 4.2$ & $88.7 \pm 4.7$ & $-0.04[-1.4 ; 1.3]$ & 0.96 \\
\hline & 2 & $89.3 \pm 4.2$ & $88.8 \pm 5.3$ & & \\
\hline \multirow[t]{2}{*}{$\mathrm{RR}_{\mathrm{sys}}[\mathrm{mmHg}]$} & 1 & $164.9 \pm 37.2$ & $164.8 \pm 19.9$ & $2.5[-8 ; 13]$ & 0.63 \\
\hline & 2 & $154.9 \pm 13.5$ & $160.5 \pm 21.8$ & & \\
\hline \multirow[t]{2}{*}{$\mathrm{RR}_{\text {dia }}[\mathrm{mmHg}]$} & 1 & $95.6 \pm 16.5$ & $92.3 \pm 14$ & $1.2[-5.8 ; 8.2]$ & 0.73 \\
\hline & 2 & $89.2 \pm 10.1$ & $90.7 \pm 5.8$ & & \\
\hline \multirow[t]{2}{*}{ Heart rate $[/ \mathrm{min}]$} & 1 & $86.1 \pm 20$ & $97.6 \pm 21.3$ & $-3.8[-8.6 ; 1.1]$ & 0.12 \\
\hline & 2 & $95.3 \pm 20.4$ & $91.4 \pm 14.3$ & & \\
\hline
\end{tabular}

Bold values represent significant results

$\mathrm{PaO}_{2}$ partial pressure of arterialized oxygen, $\mathrm{PaCO}_{2}$ partial pressure of arterialized carbon dioxide, $\mathrm{HCO}_{3}{ }^{-}$arterialized standard hydrogen carbonate, $\mathrm{S}_{a} \mathrm{O}_{2}$ Oxygen saturation, RRsys systolic blood pressure, RRdia diastolic blood pressure

\# Patients with long-term NIV

patients receiving high-intensity NIV therapy, in whom higher pressures were successfully applied during physical activity $[12,15]$. Therefore, technical developments with adaptation of the pressure level in pNIV devices could potentially have an effect in patients receiving long-term NIV.

Consequently, one important limitation of the current study was that it was not possible to individually 


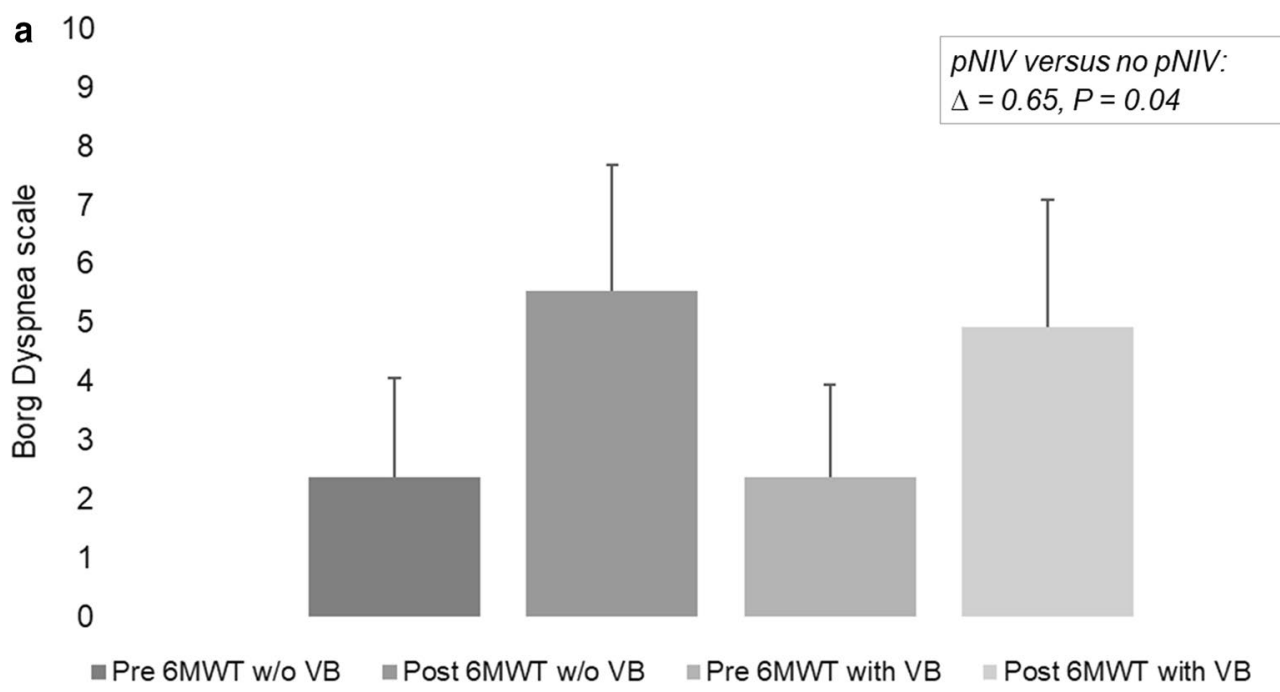

b 10

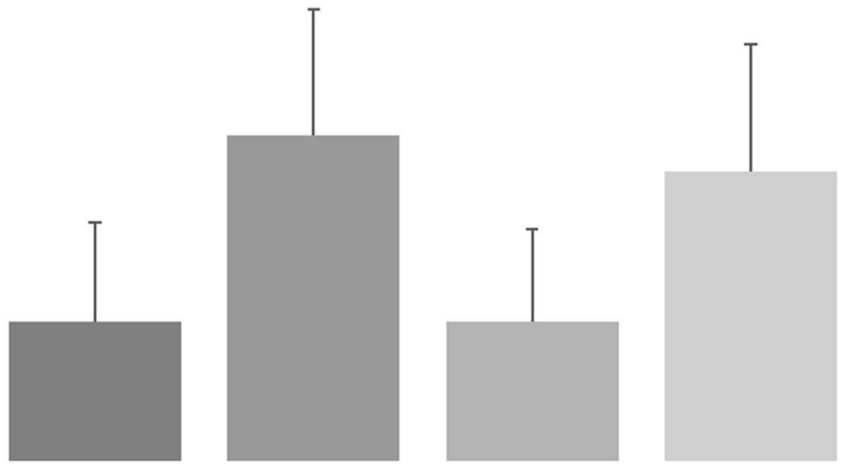

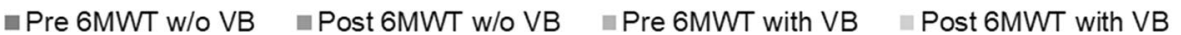

Fig. 3 a Study I: Borg Dyspnea difference before and after the 6-min walking test, with and without the pNIV device $(N=38)$. Abreviation: w/o without. b Study II: Borg Dyspnea difference before and after 6-min walking test, with and without the pNIV device $(\mathrm{N}=23)$. Abreviation: w/owithout

configure the settings for pNIV. Therefore, as technical developments continue to advance, there is the potential for even further improvements in exercise performance in COPD patients. Nevertheless, future technological developments need to incorporate the request to keep the weight of pNIV devices as low as possible, as holding more heavy devices is suggested to negatively impact on the treatment success especially in patients with severe COPD. Another limitation might also be anticipated in view of the rather short acclimatization period of $\geq 30 \mathrm{~min}$. Since acclimatization to long-term NIV typically lasts several days, this could also be true for pNIV use during walking $[24,25]$.
A recent trial that used the same pNIV device as that in the current study showed that during recovery of intermittent exercise, this device is associated with a longer exercise endurance time and reduced dynamic hyperinflation (reflected by a change in inspiratory capacity and breathlessness) in patients with moderate COPD, although the MCID was also not achieved across the entire cohort [16]. A post-hoc analysis in the same trial demonstrated that patients with a lower degree of resting hyperinflation (RV/TLC: $<56 \pm 2 \%$ ) experienced a significant improvement when the pNIV device was used during exercise, whereas patients with more severe resting hyperinflation (RV/TLC: $>65 \pm 4 \%$ ) did not show 


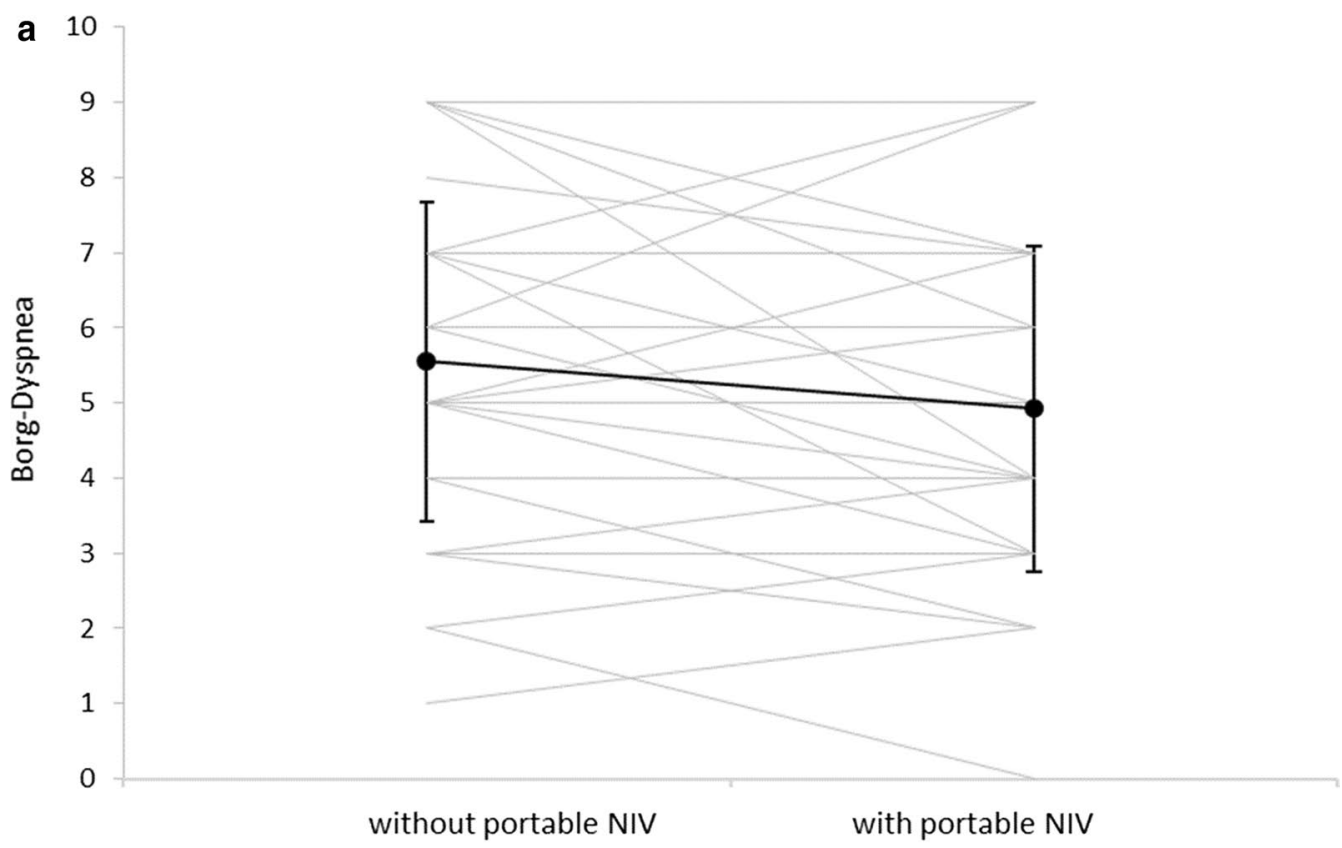

b
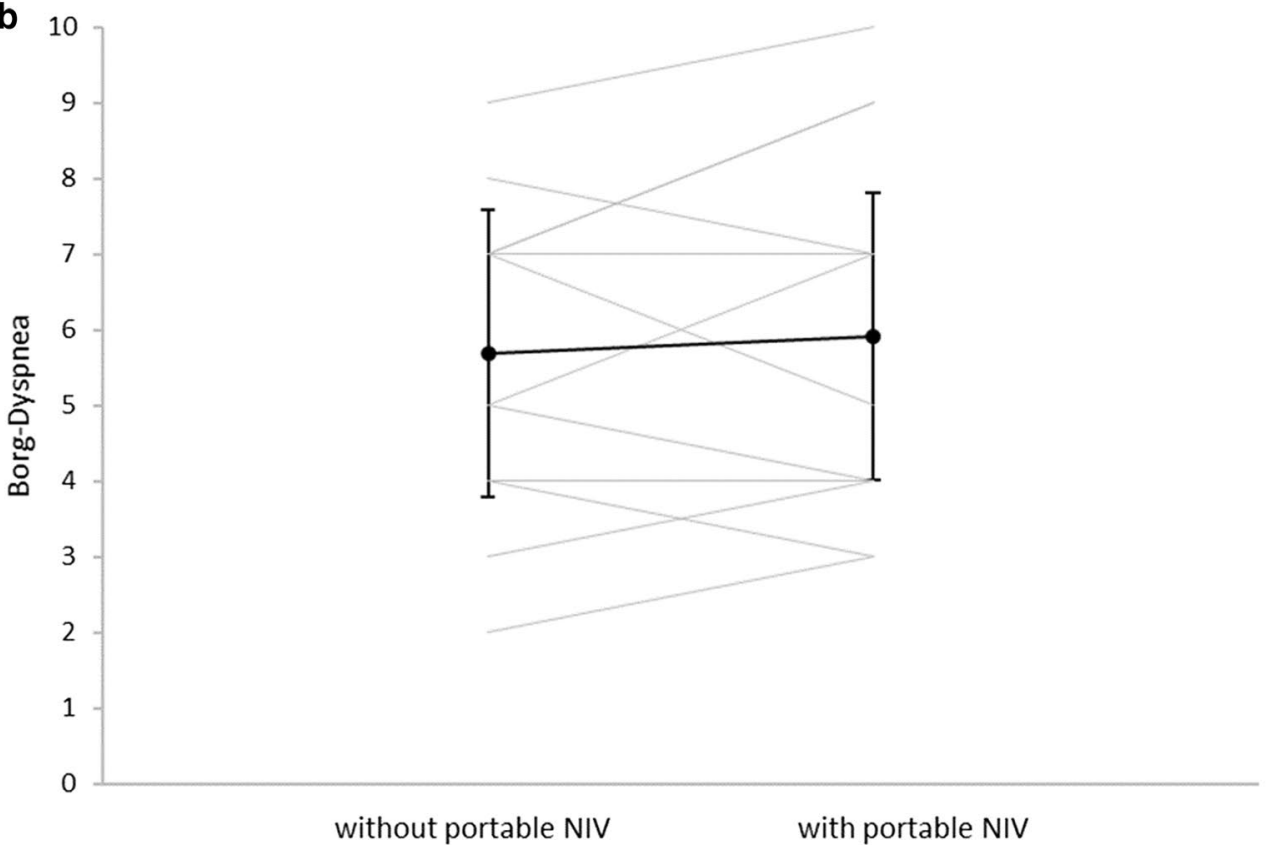

Fig. 4 a Study l: The effect of individual patients on post-exercise dyspnea, with and without the pNIV device $(N=38)$. b Study II: The effect of individual patients on post-exercise dyspnea, with and without the pNIV device $(\mathrm{N}=23)$

improvements [26]. This could also be due to the relatively small number of sample size $(n=24)[16,26]$. We therefore tested this hypothesis in our trial, but were unable to show additional benefits in patients with reduced hyperinflation. However, these results cannot be transferred to our collective without restrictions, as the patient cohorts investigated differ significantly.
Of note, a significant number of patients in the current study showed a subjective preference towards the device, despite not having experienced benefits in BDS and walking distance. This was particularly true for patients with severely impaired inspiratory muscle strength. To this end, previous findings have shown that using a pNIV device during physical activity might help to subjectively 


\section{a 450}

$$
\begin{aligned}
& 400 \\
& 350 \\
& 300
\end{aligned}
$$

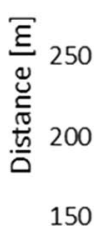
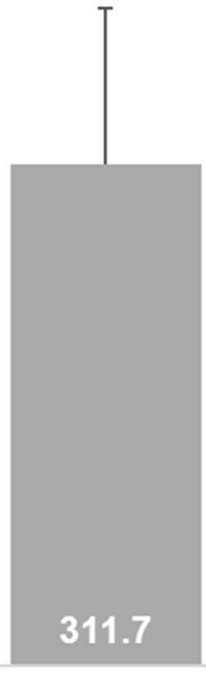

1: 6MWT without portable NIV device

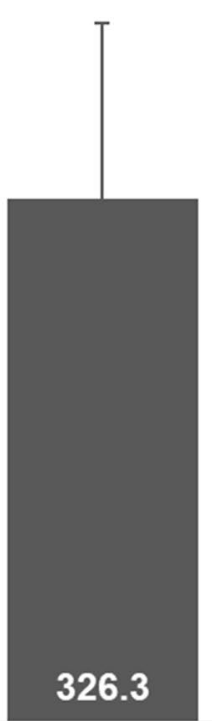

2

b

450

400

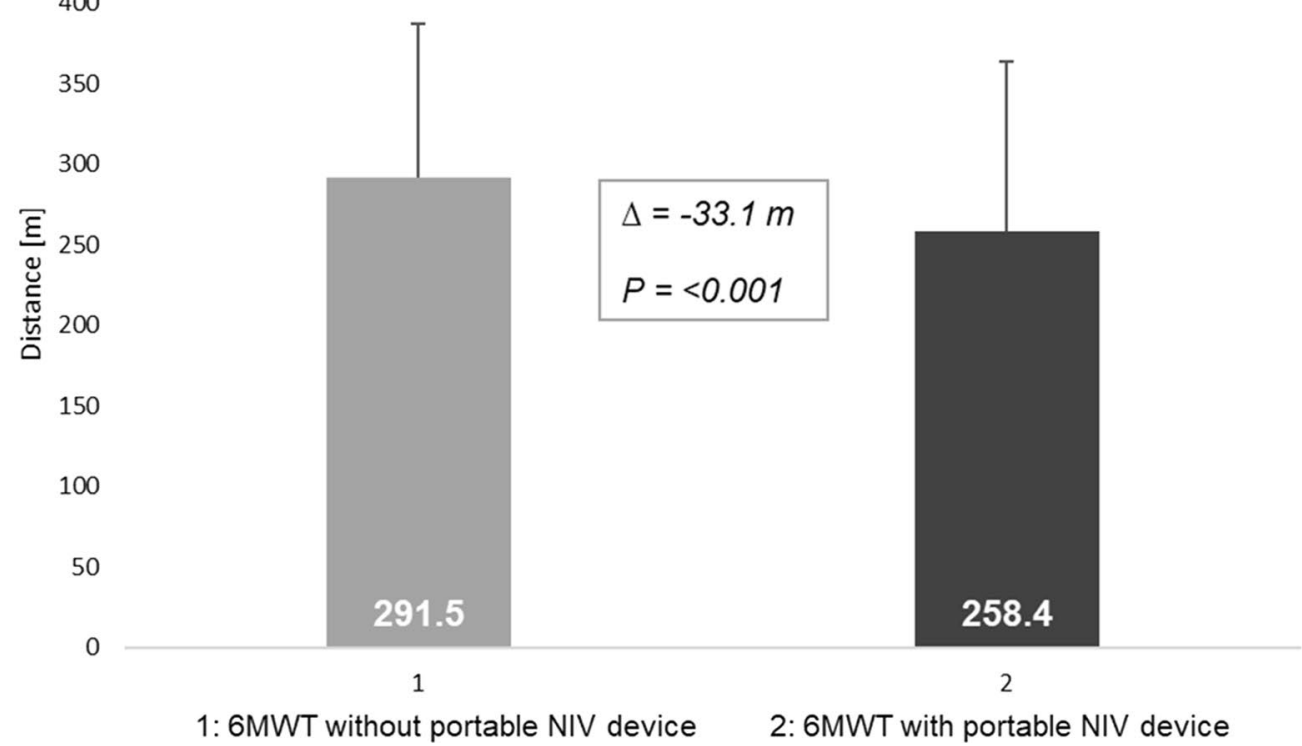

Fig. 5 a Study l: Difference in distance walked during the 6-min walking test, with and without the pNIV device $(N=38)$. b Study II: Difference in distance walked during the 6 -min walking test, with and without the pNIV device $(\mathrm{N}=23)$

alleviate the patient's fear of becoming short of breath [16]. This, however, requires further investigation in order to more reliably establish which COPD patient subgroups can benefit the most from pNIV-aided walking.

\section{Conclusion}

Portable non-invasive ventilation using a hand-held device with fixed pressure settings of $18 \mathrm{cmH}_{2} \mathrm{O}$ during inspiration and $8 \mathrm{cmH}_{2} \mathrm{O}$ during expiration bears 
the potential of improving walking distance and dyspnea during exercise testing in moderate to severe COPD patients. Patients who are not already on long-term NIV do appear to benefit more from the use of pNIV than those already receiving long-term NIV therapy. Further technical developments are required, especially those aimed at allowing adjustable pressure settings. In addition, further studies are needed to better define the subgroups that would benefit the most from this adjunctive therapy.

\begin{abstract}
Abbreviations
6MWT: 6-Minute walking test; BDS: Borg Dyspnea Scale; BMI: Body mass index; COPD: Chronic obstructive pulmonary disease; EPAP: Expiratory positive airway pressure; FEV $_{1}$ : Forced expiratory volume in one second; FVC: Forced vital capacity; GOLD: Global initiative for obstructive lung disease; $\mathrm{HCO}_{3}$ : Arterialized standard hydrogen carbonate; IPAP: Inspiratory positive airway pressure; IQR: Interquartile range; LTOT: Long-term oxygen therapy; MCID: Minimal clinical important difference; $\mathrm{NIV}$ : Non-invasive ventilation; $\mathrm{PaCO}_{2}$ : Partial pressure of arterialized carbon dioxide; $\mathrm{PaO}_{2}$ : Partial pressure of arterialized oxygen; pNIV: Portable non-invasive ventilation; $\mathrm{RR}_{\text {dia }}$ : Diastolic blood pressure; $\mathrm{RR}_{\text {sys: }}$ : Systolic blood pressure; RV: Residual volume; $\mathrm{SaO}_{2}$ : Oxygen saturation; TLC: Total lung capacity.
\end{abstract}

\section{Acknowledgements}

We acknowledge all participants for the effort they devoted to this study. We acknowledge Dr. Sandra Dieni, Ph.D. for helpful comments on the manuscript before submission.

\section{Authors' contributions}

DSM: Drafting the work, acquisition, analysis, and interpretation of data; FSM: Substantial contributions to the conception and design of the work, interpretation of data; ST: acquisition of data; CS: contributions to the conception and design of the work and statistical analysis, revising the document critically for intellectual content; WW: Substantial contributions to the conception and design of the work, interpretation of data, drafting the work, revising the document critically for intellectual content; SBS: Substantial contributions to the conception and design of the work, interpretation of data, drafting the work, revising the document critically for intellectual content. All authors read and approved the final manuscript.

\section{Funding}

Open Access funding enabled and organized by Projekt DEAL. A research grant was provided by Philips Respironics (Murrysville, PA, USA). The authors state that neither the study design, results, interpretation of the findings, nor any other subject discussed in the submitted manuscript was dependent on financial support.

\section{Availability of data and materials}

The datasets used and analyzed during the current study are available from the corresponding author on reasonable request.

\section{Declarations}

\section{Ethics approval and consent to participate}

Both study protocols were approved by the ethics committee at Witten/Herdecke University. The studies were performed in accordance with the ethical standards laid down in the Declaration of Helsinki [17] and were registered at the German Clinical Trials Registry (DRKS00013203; DRKS00012913). All patients provided written informed consent.

\section{Consent for publication}

A signed declaration of consent regarding the rights of use is available from the subjects shown.

\section{Competing interests}

DSM: open research grant from Philips Respironics/USA. FSM received speaking fees from companies dealing with mechanical ventilation products. ST: no conflicts of interest. CS: no conflicts of interest. WW: received speaking fees from companies dealing with mechanical ventilation products. SBS: received travel grants from companies dealing with mechanical ventilation products. The Cologne study group (DSM, SBS, FSM and WW) received open research grants from Weinmann/Germany, Vivisol/Germany, Heinen und Löwenstein/ Germany, VitalAire/Germany, and Phillips Respironics/USA.

\section{Author details}

${ }^{1}$ Department of Pneumology, Cologne Merheim Hospital, Kliniken der Stadt Köln gGmbH, Witten/Herdecke University, Faculty of Health/School of Medicine, Cologne, Germany. ${ }^{2}$ Clinical Trials Unit, Medical Center - University of Freiburg, Faculty of Medicine, University of Freiburg, Freiburg, Germany.

Received: 3 February 2021 Accepted: 8 April 2021

Published online: 26 April 2021

\section{References}

1. Ergan B, Oczkowski S, Rochwerg B, Carlucci A, Chatwin M, Clini E, Elliott M, Gonzalez-Bermejo J, Hart N, Lujan M, Nasilowski J, Nava S, Pepin JL, Pisani L, Storre JH, Wijkstra P, Tonia T, Boyd J, Scala R, Windisch W. European Respiratory Society guidelines on long-term home non-invasive ventilation for management of COPD. Eur Respir J. 2019. https://doi.org/10.1183/ 13993003.01003-2019.

2. Windisch W, Geiseler J, Simon K, Walterspacher S, Dreher M, on behalf of the Guideline C. German national guideline for treating chronic respiratory failure with invasive and non-invasive ventilation - revised edition 2017: part 2. Respiration. 2017;2018(96):171-203.

3. Windisch W, Geiseler J, Simon K, Walterspacher S, Dreher M, on behalf of the Guideline C. German national guideline for treating chronic respiratory failure with invasive and non-invasive ventilation: revised edition 2017-part 1. Respiration. 2017;2018(96):66-97.

4. Dreher M, Storre JH, Schmoor C, Windisch W. High-intensity versus lowintensity non-invasive ventilation in patients with stable hypercapnic COPD: a randomised crossover trial. Thorax. 2010;65:303-8.

5. Schwarz SB, Magnet FS, Windisch W. Why high-intensity NPPV is favourable to low-intensity NPPV: clinical and physiological reasons. COPD. 2017;14:389-95.

6. Gloeckl R, Andrianopoulos V, Stegemann A, Oversohl J, Schneeberger T, Schoenheit-Kenn U, Hitzl W, Dreher M, Koczulla AR, Kenn K. High-pressure non-invasive ventilation during exercise in COPD patients with chronic hypercapnic respiratory failure: a randomized, controlled, cross-over trial. Respirology. 2019;24:254-61.

7. Vitacca M, Kaymaz D, Lanini B, Vagheggini G, Ergün P, Gigliotti F, Ambrosino N, Paneroni M. Non-invasive ventilation during cycle exercise training in patients with chronic respiratory failure on long-term ventilatory support: a randomized controlled trial. Respirology. 2018;23:182-9.

8. Koopman M, Spruit MA, Franssen FME, Delbressine J, Wouters EFM, Mathew D, Vink A, Vanfleteren L. Effects of non-invasive ventilation combined with oxygen supplementation on exercise performance in COPD patients with static lung hyperinflation and exercise-induced oxygen desaturation: a single blind, randomized cross-over trial. J Clin Med. 2019. https://doi.org/10.3390/jcm8112012.

9. Corner E, Garrod R. Does the addition of non-invasive ventilation during pulmonary rehabilitation in patients with chronic obstructive pulmonary disease augment patient outcome in exercise tolerance? A literature review. Physiother Res Int. 2010;15:5-15.

10. Hawkins P, Johnson L, Nikoletou D, Hamnegård C, Sherwood R, Polkey M, Moxham J. Proportional assist ventilation as an aid to exercise training in severe chronic obstructive pulmonary disease. Thorax. 2002;57:853-9.

11. Keilty SE, Ponte J, Fleming TA, Moxham J. Effect of inspiratory pressure support on exercise tolerance and breathlessness in patients with severe stable chronic obstructive pulmonary disease. Thorax. 1994;49:990-4.

12. Dreher $\mathrm{M}$, Storre JH, Windisch W. Noninvasive ventilation during walking in patients with severe COPD: a randomised cross-over trial. Eur Respir J. 2007;29:930-6. 
13. Hernandez P, Maltais F, Gursahaney A, Leblanc P, Gottfried SB. Proportional assist ventilation may improve exercise performance in severe chronic obstructive pulmonary disease. J Cardiopulm Rehabil Prev. 2001;21:135-42

14. van't Hul A, Kwakkel G, Gosselink R. The acute effects of noninvasive ventilatory support during exercise on exercise endurance and dyspnea in patients with chronic obstructive pulmonary disease: a systematic review. J Cardiopulm Rehabil Prev. 2002;22:290-7.

15. Dreher M, Doncheva E, Schwoerer A, Walterspacher S, Sonntag F, Kabitz $\mathrm{HJ}$, Windisch W. Preserving oxygenation during walking in severe chronic obstructive pulmonary disease: noninvasive ventilation versus oxygen therapy. Respiration. 2009;78:154-60.

16. Vogiatzis I, Chynkiamis N, Armstrong M, Lane ND, Hartley T, Gray WK, Bourke SC. Intermittent use of portable NIV increases exercise tolerance in COPD: a randomised, cross-over trial. J Clin Med. 2019. https://doi.org/ 10.3390/jcm8010094.

17. Williams JR. The declaration of Helsinki and public health. Bull World Health Organ. 2008;86:650-2.

18. Halpin DM, Criner GJ, Papi A, Singh D, Anzueto A, Martinez FJ, Agusti A, Vogelmeier CF, Committee GS. Global initiative for the diagnosis, management, and prevention of chronic obstructive lung disease: the 2020 GOLD science committee report on COVID-19 \& COPD. Am J Respir Crit Care Med. 2020. https://doi.org/10.1164/rccm.202009-3533SO.

19. Vogelmeier C, Buhl R, Burghuber O, Criee CP, Ewig S, Godnic-Cvar J, Hart S, Herth F, Kardos P, Kenn K, Nowak D, Rabe KF, Studnicka M, Watz H, Welte T, Windisch W, Worth $\mathrm{H}$, unter Mitwirkung der folgenden wissenschaftlichen Fachgesellschaften: Deutsche Gesellschaft fur Arbeitsmedizin und Umweltmedizin e V, Deutsche Gesellschaft fur Rehabilitationswissenschaften e V. Guideline for the diagnosis and treatment of COPD patients - issued by the German Respiratory Society and the German Atemwegsliga in Cooperation with the Austrian Society of Pneumology. Pneumologie. 2018;72:253-308.

20. Guyatt GH, Pugsley SO, Sullivan MJ, Thompson PJ, Berman L, Jones NL, Fallen EL, Taylor DW. Effect of encouragement on walking test performance. Thorax. 1984;39:818-22.
21. Hardy WJ, J. MS Clinical research; Respironics, P. [cited 2020 22.07.2020]. Available from https://usermanual.wiki/Philips/vitabreathwhitepaper a4final.3771554293.pdf.

22. Cazzola M, MacNee W, Martinez FJ, Rabe KF. Outcomes for COPD pharmacological trials: from lung function to biomarkers. Rev Port Pneumol. 2008;14:579-83.

23. Polkey MI, Spruit MA, Edwards LD, Watkins ML, Pinto-Plata V, Vestbo J, Calverley PM, Tal-Singer R, Agusti A, Bakke PS, Coxson HO, Lomas DA, MacNee W, Rennard S, Silverman EK, Miller BE, Crim C, Yates J, Wouters EF, Celli B, Evaluation of CLtIPSESI. Six-minute-walk test in chronic obstructive pulmonary disease: minimal clinically important difference for death or hospitalization. Am J Respir Crit Care Med. 2013;187:382-6.

24. Duiverman ML, Vonk JM, Bladder G, van Melle JP, Nieuwenhuis J, Hazenberg A, Kerstjens HA, van Boven JF, Wijkstra PJ. Home initiation of chronic non-invasive ventilation in COPD patients with chronic hypercapnic respiratory failure: a randomised controlled trial. Thorax. 2020;75:244-52.

25. van der Leest S, Duiverman ML. High-intensity non-invasive ventilation in stable hypercapnic COPD: evidence of efficacy and practical advice. Respirology. 2019;24:318-28.

26. Chynkiamis N, Armstrong M, Hume E, Alexiou C, Snow L, Lane ND, Hartley T, Bourke SC, Vogiatzis I. Effect of portable non-invasive ventilation on exercise tolerance in COPD: one size does not fit all. Respir Physiol Neurobiol. 2020;277:103436

27. Moher D, Schulz KF, Altman DG. The CONSORT statement: revised recommendations for improving the quality of reports of parallel-group randomised trials. Lancet. 2001;357:1191-4.

\section{Publisher's Note}

Springer Nature remains neutral with regard to jurisdictional claims in published maps and institutional affiliations.
Ready to submit your research? Choose BMC and benefit from:

- fast, convenient online submission

- thorough peer review by experienced researchers in your field

- rapid publication on acceptance

- support for research data, including large and complex data types

- gold Open Access which fosters wider collaboration and increased citations

- maximum visibility for your research: over 100M website views per year

At BMC, research is always in progress.

Learn more biomedcentral.com/submissions 